\title{
Patients' perspectives on telephone outpatients during a pandemic
}

\author{
Sophie Whitehead ${ }^{1}\left[\right.$ Paul Gravestock ${ }^{1} \cdot$ Chris Harding $^{1} \cdot$ Rajan Veeratterapillay $^{1}$
}

Received: 23 December 2021 / Accepted: 1 January 2022 / Published online: 14 January 2022

(c) The Author(s), under exclusive licence to Royal Academy of Medicine in Ireland 2022

The COVID-19 pandemic required rapid adaptation of healthcare provision to ensure patient and staff safety. The Freeman Hospital provides tertiary urological services for the North East of the UK. In response to the COVID19 pandemic, face to face outpatient appointments were switched to telephone appointments in line with government advice [1].

This study aimed to assess patient satisfaction with remote appointments at the Freeman Hospital during the COVID-19 pandemic.

One hundred seventy-three patients were contacted consecutively. Those who did not answer within two attempts or declined participation were excluded. One hundred patients were successfully contacted, with a $58 \%$ response rate. All the patients were contacted within 1 week of their telephone appointment, to minimise recall bias.

Participants answered a nine-question survey. This was based on validated patient satisfaction surveys [2]. Appointment convenience, ease of communication and overall satisfaction were assessed. Six of the nine questions were yes/ no answers, and the remaining three questions used a Likert scale (1-5), where 1 was not at all satisfied, and 5 was very satisfied.

Results and questions asked are summarised in Table 1.

The rates of satisfaction were subdivided into patients with or without previous experience of face-to-face appointments. In both groups, $94 \%$ were very satisfied or satisfied.
More patients with previous in person appointments were very satisfied, $77 \%$ vs. $63 \%$ without.

The median age of respondents was 67 (range 21-91). Higher satisfaction was reported amongst those older than $67(n=49), 86 \%$ were very satisfied and $14 \%$ satisfied. Of the participants 67 or younger $(n=51), 69 \%$ were very satisfied, $19 \%$ satisfied, $4 \%$ ambivalent, and $8 \%$ not satisfied. More patients over 67 would have preferred in person appointments than those under 67, 53\% and $41 \%$, respectively. Between age groups, similar proportions preferred telephone clinics, (33\% vs. $31 \%,>67$ vs. $\leq 67$ years old), $14 \%$ and $19 \%$, respectively had, no preference.

Other studies reflect high patient satisfaction with telephone consultations undertaken throughout COVID-19 [3-10].

In conclusion, whilst COVID-19 necessitated a shift to telephone consultations, this study supports that telephone clinics are a valuable means of patient contact. Patients rated convenience, communication and satisfaction highly, and the majority of patients would engage in future telephone clinics.

It is recommended that initial assessments and new patient clinics are performed face to face, whereas routine follow-up appointments may be optimum candidates for telephone clinics.

Sophie Whitehead

Sophie.whitehead6@nhs.net

1 Department of Urology, Freeman Hospital, Newcastle, UK 
Table 1 Summary of results

\begin{tabular}{|c|c|c|c|c|c|}
\hline \multirow[b]{2}{*}{ Question } & \multicolumn{3}{|c|}{ Yes/No } & & \\
\hline & Yes & No & Don't Mind & & \\
\hline Is this your first telephone consultation? & $48 \%$ & $52 \%$ & & & \\
\hline Have you had a face-to-face appointment with the urology service before? & $81 \%$ & $19 \%$ & & & \\
\hline Were you clear at the end of the consultation about the plan going forward? & $92 \%$ & $8 \%$ & & & \\
\hline Did everything go as you expected? & $88 \%$ & $12 \%$ & & & \\
\hline Would you be happy to engage via telephone clinic in the future? & $94 \%$ & $6 \%$ & & & \\
\hline \multirow[t]{3}{*}{ Do you think you would have preferred a face-to-face appointment? } & $47 \%$ & $36 \%$ & $17 \%$ & & \\
\hline & \multicolumn{5}{|c|}{ Likert scale* } \\
\hline & 5 & 4 & 3 & 2 & 1 \\
\hline How would you rate the convenience of the telephone consultation? & $68 \%$ & $26 \%$ & $1 \%$ & $0 \%$ & $5 \%$ \\
\hline How would you rate how you were listened too? & $77 \%$ & $15 \%$ & $7 \%$ & $1 \%$ & $0 \%$ \\
\hline Overall, how satisfied were you with the telephone consultation? & $77 \%$ & $17 \%$ & $2 \%$ & $4 \%$ & $0 \%$ \\
\hline
\end{tabular}

$* 5$ - Very satisfied, 1 - very dissatisfied

Author contribution S. Whitehead: data collection or management, data analysis and manuscript writing/editing. P. Gravestock: data collection or management, data analysis and manuscript writing/editing. R. Veeratterapillay: protocol/project development and manuscript writing/editing. C. Harding: protocol/project development and manuscript writing/editing.

\section{References}

1. Public Health England (2020, August) COVID-19: guidance for the remobilisation of services within health and care settings: infection prevention and control recommendations (version 1.2). Available from: https://static1.squarespace.com/static/5e6613a1dc 75b87df82b78e1/t/5f4638aab1f16e303266804b/1598437551 598/COVID-19_Infection_prevention_and_control_guidance_ FINAL_PDF_20082020\%5B1\%5D.pdf

2. Dell-Kuster S, Sanjuan E, Todorov A et al (2014) Designing questionnaires: healthcare survey to compare two different response scales. BMC Med Res Methodol 14:96. https://doi.org/10.1186/ 1471-2288-14-96

3. Locke J, Herschorn S, Neu S et al (2020) Patients' perspective of telephone visits during the COVID-19 pandemic. Can Urol Assoc J 14(9):E402-E406. https://doi.org/10.5489/cuaj.6758. (PMID: 32931728; PMCID: PMC7492037)

4. Melian C, Frampton C, Wyatt MC, Kieser D (2021) Teleconsultation in the management of elective orthopedic and spinal conditions during the COVID-19 pandemic: prospective cohort study of patient experiences. JMIR Form Res 5(6):e28140. https://doi. org/10.2196/28140. (PMID: 34048355; PMCID: PMC8208469)

5. Chesnel C, Hentzen C, Le Breton F et al (2021) Efficiency and satisfaction with telephone consultation of follow-up patients in neuro-urology: experience of the COVID-19 pandemic. Neurourol
Urodyn 40(3):929-937. https://doi.org/10.1002/nau.24651. (Epub 6 Mar 2021 PMID: 33675263)

6. Wignall D, Lee L, Gkentzis A et al (2020) A review of telephone urological follow-up in a District General Hospital during the COVID-19 pandemic [published online ahead of print, 9 Nov 2020]. SN Compr Clin Med 1-7. https://doi.org/10.1007/ s42399-020-00628-y

7. Patel S, Douglas-Moore J (2020) A reflection on an adapted approach from face-to-face to telephone consultations in our Urology Outpatient Department during the COVID-19 pandemic - a pathway for change to future practice? BJU Int 126(3):339341. https://doi.org/10.1111/bju.15119. Pub 4 Aug 2020 (PMID: 32469096; PMCID: PMC7283724)

8. Heeno E, Biesenbach I, Englund C et al (2021) Patient perspective on telemedicine replacing physical consultations in urology during the COVID-19 lockdown in Denmark. Scand J Urol. https:// doi.org/10.1080/21681805.2021.1906317

9. Tamayo AL, Espinós EL, González ER et al (2020) Evaluation of teleconsultation system in the urological patient during the COVID-19 pandemic. Actas Urol Esp (Engl Ed) 44(9):617-622. English, Spanish. https://doi.org/10.1016/j.acuro.2020.06.002. Epub 18 Jun 2020 (PMID: 32650954; PMCID: PMC7301061)

10. Vusirikala A, Ensor D, Asokan AK et al (2021) Hello, can you hear me? Orthopaedic clinic telephone consultations in the COVID-19 era- a patient and clinician perspective. World J Orthop 12(1):24-34. https://doi.org/10.5312/wjo.v12.i1.24. (PMID: 33520679; PMCID: PMC7814312)

Publisher's Note Springer Nature remains neutral with regard to jurisdictional claims in published maps and institutional affiliations. 